\title{
ПРОБЛЕМА СОХРАНЕНИЯ ВЫСОКОГО УРОВНЯ ПРАВОВОЙ КУЛЬТУРЫ У ЛИЦ, ИМЕЮЩИХ ЛИЦЕНЗИЮ НА ИСПОЛЬЗОВАНИЕ ОРУЖИЯ
}

\section{THE PROBLEM OF MAINTAINING A HIGH LEVEL OF LEGAL CULTURE AMONG PERSONS WHO HAVE A LICENSE TO USE WEAPONS}

T. Tsvetikova

Summary. People who have a permit to store and carry weapons, primarily firearms, have recently caused increased concern among state authorities and society, since judicial statistics are increasingly recording cases related to their unauthorized use. At the same time, individual or mass victims are recorded among ordinary citizens who are not involved in the commission of offenses that can be qualified as dangerous or especially dangerous criminal acts. As a result, in their minds, legal culture gives way to legal nihilism, characteristic of the medieval state of "war of all against all". In order to prevent such changes in the personality of citizens who have weapons for domestic or professional needs, it is necessary to develop measures aimed not only at changing behavioral reactions, but also at a conscious level.

Keywords: "legal culture", "legal nihilism", "persons who have the right to keep, carry and use weapons for professional or domestic purposes", "development of measures to stabilize the situation associated with maintaining a high level of legal culture among persons with firearms or cold weapons".

\section{Введение}

Л ица, имеющие лицензию на хранение и ношение оружия, в последнее время, как в Российской Федерации, так и за рубежом вызывают беспокойство у властных структур и представителей общественности из-за его несанкционированного использования. Необходимость регулирования их поведения отражается как в нормативно-правовой базе, так и в работах ряда исследователей.

Целью данной публикации является не только раскрытие факторов, влияющих на снижение уровня правовой культуры у данной категории граждан, но также описание способов ее повышения в условиях нестабильной социально-экономической ситуации,
Цветикова Татьяна Викторовна

Аспирант, ФГБОУ ВО «Брянский государственный университет им. акад. И.Г. Петровского» tatyna.76@inbox.ru

Аннотация. Люди, имеющие разрешение на хранение и ношение оружия, прежде всего, огнестрельного, в последнее время вызывают повышенное беспокойство у государственных властных структур и общества. Все чаще фиксируются единичные или массовые жертвы среди рядовых граждан, не причастных к совершению проступков, которые могут быть квалифицированы как опасные или особо опасные преступные деяния. Становится очевидным, что в сознании владельцев оружия правовая культура уступает место правовому нигилизму, свойственному для средневекового состояния «войны всех против всех». Для того, чтобы предотвратить подобные изменения личности граждан, имеющих оружие для бытовых или профессиональных нужд, необходимо разрабатывать мероприятия, направленные не только на изменения поведенческих реакций, но и на сознательном уровне.

Ключевые слова: «правовая культура», «правовой нигилизм», «лица, имеющие право на хранение, ношение и применение оружия в профессиональных или бытовых целях», «разработка мероприятий по стабилизации положения, связанного с сохранением высокого уровня правовой культуры у лиц, имеющих огнестрельное или холодное оружие».

что, не в последнюю очередь, связано с последствиями пандемии COVID - 19.

Задачи исследования состоят в следующем: раскрытие условий предоставления различных видов оружия гражданам в Российской Федерации и за рубежом; рассмотрение различных видов и типов оружия в современном мире и его опасность для общества и государства; представление практических рекомендаций по сохранению и повышению уровня правовой культуры у граждан, обладающих оружием по различным основаниям.

Объектом исследования являются субъекты, наделенные правами на хранение, ношение и применение оружия по различным основаниям. Предметом изу- 
чения представлена проблема сохранения высокого уровня правовой культуры у соответствующей категории граждан.

Методологические приемы, использованные в публикации, включают описание, анализ, синтез, статистические приемы, индукцию и дедукцию, обобщения, моделирование.

Работа построена на привлечении как нормативно-правовых актов, касающихся предоставления, ношения или хранения оружия, так и публикации и монографий на эту тему.

Если проследить историю установления контроля за оборотом оружия, то можно увидеть следующую картину. В 1924 г. огнестрельное оружие разрешалось выдавать только сотрудникам ОГПУ. С 1940 г. стали выдаваться разрешения на наличие охотничьих ружей. Когда в 1953 г. для их получения стало необязательным предъявление охотничьих билетов, стал фиксироваться свободный оборот указанного оружия, что привело к росту убийств с его применением в период с 1953 по 60-е гг. ХХв.

Смена руководства советского государства вновь способствовала усилению законодательного контроля за приобретение, хранением, ношением и оборотом оружия, что продолжалось с 1969 по 1986 гг.

В 90-ее гг. ХХв. вновь отмечаются случаи несанкционированного использования огнестрельного оружия. [1] Тем не менее, 24.07.2012 г. депутат Государственной Думы А. Торшин выступил за разрешение наличия оружия у гражданского населения. Таким образом, можно сказать, что политика руководства российского государства в разные исторические периоды не была последовательной относительно решения вопроса о хранении, ношении и применении оружия гражданским населением. [2]

В настоящее время виды оружия, условия его приобретения, хранения, ношения и применения, а также конструкторские особенности регламентированы законодательно. [3, ст. 1-9]

Казалось бы, все нюансы по предоставлению прав населения в отношении оружия государством были учтены. Тем не менее, на практике участились случаи несанкционированного использования огнестрельного и холодного оружия, как рядовыми гражданами, так и сотрудниками соответствующих органов и структур.

Одним из «громких» дел, касающемуся несанкционированного использования не только огнестрель- ного, но и взрывчатого оружия можно считать террористический акт, совершенный в Беслане (Северная Осетия) в период с 01.09 по 03.09. 2004 г., начало которого совпало с торжественной линейкой, посвященной началу учебного года. [4]

С окончанием активной военной компании в Чеченской республике количество массовых террористических актов сократилось. Тем не менее, периодически фиксируются случаи несанкционированного применения холодного и огнестрельного оружия, как гражданским населением, так и представителями военных и приравненных к ним организаций.

Так, 27 апреля 2009 г. майор милиции Денис Евсюков в супермаркете «Остров» на Шипиловской улице совершил убийство 2 человек и покушение на убийство еще 22.

Причины трагедии очевидцы и сослуживцы видели не столько в событиях, предшествовавших ей, в частности, ссоры с женой, сколько в личности преступника. [5]

Похожий случай произошел в июне 2017 года в подмосковном поселке Кратово, где бывший сотрудник МЧС открыл стрельбу, в результате которой стали жертвами как минимум четыре человека. При этом использовалось охотничье оружие, хранение и ношение которого не требует особых ограничений.

Тем не менее, в настоящее время расширен список должностных лиц, которым разрешается иметь при себе служебное оружие и при необходимости пользоваться им. Так, служебным оружием разрешено пользоваться судьям. Основной целью его предоставления является обеспечении гарантии защиты здоровья и жизни судьи и членов его семьи, а также их имущества от противоправных посягательств, что регламентировано Законом РФ от 26.06.1992 г. № 3132-1 «О статусе судей в Российской Федерации».

Сама процедура предоставления оружия судьям закреплена нормативной базой. [7]

Однако, все перечисленные ограничения и условия предоставления оружия должностным лицам не приводят к быстрой стабилизации положения, что можно увидеть в анализе противоправных деяний, совершенных с применением оружия в период с 2014 по 2018 гг. [8].

А.И. Ситникова, анализируя в своей публикации случаи незаконного изготовления, приобретения, оборота, хранения, применения не только огнестрельного, но также холодного и взрывного оружия. Гражданским 
населением допускалось применение вооружения для самообороны, при этом фиксировались случаи нарушения пределов допустимой обороны, что приводило на практике к применению ограниченной юридической ответственности к виновным лицам. [9]

Муркштис М.И. в своей статье, посвященной генезису и современному состоянию незаконного оборота оружия и его предупреждению, выделяет периоды роста или снижения соответствующих противоправных деяний с указанием их причин. [10]

Уполномоченными ведомствами стали регистрировались ситуации, когда преступниками становились учащиеся образовательных организаций разных уровней или представители молодежи. Так, 03.02.2014 г. десятиклассник С. Гордеев пришел в школу с карабином отца. Он застрелил учителя географии, а затем приехавшего на его задержание полицейского, второй сотрудник силового ведомства был тяжело ранен.

В ходе судебного разбирательства преступник был признан психически больным и ему были назначены медицинские меры принудительного характера. Выяснилось также, что его отец, являясь сотрудником правоохранительной системы, имел у себя в доме целый арсенал и научил сына пользоваться оружием. [11]

Обратимся также к рассмотрению происшествия в Казани, которое имело место в мае 2021 года, когда бывший учащийся гимназии И.Р. Гулявиев расстрелял учеников того образовательного учреждения, в котором ранее обучался и сам. В результате этой трагедии погибли два педагога и семеро детей. [12]

Участились случаи несанкционированного использования огнестрельного оружия в учреждениях пенитенциарной системы Российской Федерации. [13]

Во всех перечисленных ситуациях субъекты, имеющие право на использование оружия или применяющие его незаконно, демонстрировали правовой нигилизм, который выражался, главным образом, в пренебрежении чужими жизнями.

По наблюдениям специалистов, только 18,8\% соответствующих деяний относилась к сфере бизнеса. Основную массу составляли бытовые и корыстно-бытовые преступления, участниками которых становились близкие родственники или лица, между которыми существовали приятельские отношения. Если речь шла о должностных лицах, то здесь обращалось внимание на профессионализм личной охраны или сотрудников службы безопасности соответствующих предприятий и организаций.
Значительную роль на рост преступлений с применением оружия играют также виктимологические признаки жертв убийств по найму. [14]

Действующая законодательная база Российской Федерации предполагает повышенную регламентацию случаев предоставления лицензий на хранение и ношение оружия, прежде всего соответствующими категориями должностных лиц. Сотрудники правоохранительных органов руководствуются при применении оружия, помимо Федерального закона Российской Федерации «Об оружии», следующими нормативно-правовыми актами: Основными принципами применения силы и огнестрельного оружия должностными лицами по поддержанию правопорядка; Кодексом поведения должностных лиц по поддержанию правопорядка; Руководящими принципами для эффективного осуществления Кодекса поведения должностных лиц по поддержанию правопорядка. Данные документы установлены и на международном уровне. Также к приведенному перечню следует отнести статью 23 Федерального закона «О полиции».

Прожетерин И.А. проводит изучение доктринального толкования второй поправки к Конституции США, касающейся хранения и ношения огнестрельного оружия. [15] Согласно действующей на момент принятия второй поправки к Конституции США ситуации, оружие в государстве могли носить как сотрудники милиции («well regulatet Militia»), так и обычные люди. Близко по отношению к термину «полиция» американское законодательство рассматривает понятие «народное ополчение».

B XXв. появилась новая трактовка права на оружие в США: «народное ополчение» теперь рассматривалось в контексте полномочий штатов иметь определенный арсенал, но отрицало подобную возможность для гражданского населения.

Предоставление права гражданам на ношение оружия было продиктовано, с одной стороны, угрозой массовых восстаний рабов на Юге государства; с другой - необходимостью защиты от мигрантов на Севере, которые не всегда прибывали с добрыми намерениями. В результате было отработано коллективное право на хранение и ношение оружия, которое, как раз предполагало его использование в экстраординарных случаях.

Верховный Суд США окончательно утвердил индивидуальное право каждого гражданина на хранение и ношение оружия, что, одновременно подразумевало и возникновение юридической ответственности за его несанкционированное применение. Если привести статистические данные о количестве оружия на 100 чело- 
век и числа убийств на 100 тыс. жителей соответствующих государств, то можно увидеть следующую картину. В США при 120 единиц оружия на 100 человек фиксируется 4,7 убийств в год на 100 тыс. жителей.

Что касается Швеции, Австрии, Исландии, Германии, то в них на 100 человек предоставляется, соответственно, 31,6; 30,4; по 30,3 единиц огнестрельного оружия, а убийства составляют 0,7; 0,9; 0,3 и 0,8 на 100 тыс. человек. Исключение зафиксировано только в Йемене, где при 54,8 единиц оружия на 100 жителей приходится 4,8 убийств в год на 100 тыс. человек, что превышает негативную тенденцию по данному виду преступлений даже в США.

Строго относится к выдаче разрешений на хранение и ношение оружия Британия. [16] В то же время в указанном государстве фиксируется большое число самоубийств с применением огнестрельного оружия, что свидетельствует о наличии психо-неврологических расстройств у граждан, имеющих личное вооружение.

Наконец, В.В.Оксамытный, рассматривая в одной из своих статей особенности формирования правовой культуры Израиля, где в армии служат не только мужчины, но и женщины, указывает на влияние в рамках организации воспитательного процесса, который он считает основой складывания культурных ценностей, не только действующих нормативно-правовых актов, включая исполнительные документы и судебные акты, но также и религиозные нормы, что роднит данную правовую систему с мусульманским правом. [17]

В целом приведенные сведения об уровне правовой культуры лиц, имеющих право на хранение, ношение и применение, прежде всего, огнестрельного оружия предполагают экстренное проведение профилакти- ческих мер в среде разных категорий населения, как в Российской Федерации, так и за рубежом.

\section{Выводы и результаты}

Для формирования высокого уровня правовой культуры у лиц, имеющих разрешение на хранение и ношение оружия необходимо проводить следующие мероприятия: совершенствовать законодательство общего и специфического характера, регулирующих проблемы предоставления и контроля оборота оружия; проводить обязательные психиатрическую и наркологическую экспертизы лиц, подавших заявление на оформление им разрешений на оружие, независимо от целей приобретения; для сотрудников служб, ношение и применения оружия в которых является обязательным атрибутом деятельности, проводить систематические беседы с психологами и медицинские осмотры по своевременному выявлению расстройств нервной системы, препятствующих выдаче разрешений на оружие; разрабатывать программы профессиональной подготовки сотрудников в сферах деятельности, связанных с использованием оружия, уделяя особое внимание его применению; сотрудникам силовых министерств и ведомств необходимо оперативно реагировать на информацию о готовящихся террористических актах, не относиться к ней как к ложным сигналам; при совершении лицом, имеющим оружие на законных основаниях или нелегально, тщательно исследовать причины, побудившие его к совершению соответствующего деяния, включая эмоциональную составляющую, с целью предупреждения совершения им подобных эксцессов в будущем; наконец, если народ какого-либо государства руководствуется в своей политике, в том числе правовой доктрине, религиозными нормами, они не должны иметь негативный смысл, ориентированный на уничтожение других людей, в т.ч. по религиозным мотивам.

\section{ЛИТЕРАТУРА}

1. Легализация оружия в России: история и современость.//Электронный ресурc]: URL: topwar.ru (Дата обращения: 13.08.2021 г.);

2. Как на «диком Западе».//[Электронный ресурс]: URL: rg.ru/2012/07/25/orujie.html (Дата обращения: 13.08.2021г.);

3. Федеральный закон РФ от 13.12.1996 г. № 150 - Ф3 «06 оружии» (в ред. от 08.12 .2020 г. № 403 - Ф3) — Ст. 1-9;

4. Террористический акт в Беслане.//[Электронный ресурc]: URL: https://ru.wikipedia.org/wiki(Дата обращения: 13.06 .2021 г.);

5. Дело Евсюкова.//[Электронный ресурc]: URL: https://ru.wikipedia.org/wiki (Дата обращения: 13.06.2021 г.);

6. Постановление Правительства РФ от 20.02.2019 г. № 170 «0б осуществлении мер по обеспечению судей служебным оружием и признании утратившими силу некоторых актов Правительства Российской Федерации». //[Электронный ресурс]: URL: base.garant.ru/72180696 (Дата 0бращения: 13.06.2021 г.);

7. Федеральный закон РФ от 03.07.2016 г. № 226 — Ф3 «0 войсках национальной гвардии Российской Федерации» (ред. от 01.07.2021 г.) //[Электронный ресурc]: URL: https://legalacts.ru (Дата обращения: 13.06 .2021 г.);

8. Юсупова 0.А. Современное состояние и тенденции развития преступности, связанной с незаконным оборотом оружия.// «Вестник Сибирского юридического института МВД России», 2019, № 3.- - . 46-53;

9. Ситникова А.И. Незаконное приобретение, передача, сбыт, хранение, перевозка или ношение оружия, его основных частей, боеприпасов: вопросы квалификации.//Правовая система «Консультант- Плюс» (Дата обращения: 19.08.2021г.); 
10. Муркштис М.И. Незаконный оборот оружия и боеприпасов в России (генезис, современное состояние). //[Электронный pecypc]: URL: суberleninka.ru (Дата обращения: 13.06 .2021 г.);

11. Стрельба в школе № 263.// [Электронный ресурс]: URL: https://ru.wikipedia.org/wiki (Дата обращения: 13.08.2021 г.);

12. Массовое убийство в гимназии № 175 (Республика Татарстан).// [Электронный ресурс]: URL: https://ru.wikipedia.org/wiki (Дата обращения: 13.08.2021 г.);

13. 13.Горбань Д.В. Проблемы предупреждения проникновения запрещенных предметов на территорию учреждений уголовно- исполнительной системы и пути их решения.// [Электронный ресурc]: URL: https://cyberleninka.ru/(Дата обращения: 16.08.2021 г.)

14. Ильин И.С. Виктимологические аспекты убийств по найму. Автореферат диссертации на соискание ученой степени кандидата юридических наук по специальности 12.00.08 - уголовное право и криминология; уголовно- исполнительное право.— M, 2008; [Электронный pecypc]: URL: dissers.ru (Дата обращения: 14.08 .2021 г.);

15. Прожетерин И.А. (студент 2-го курса магистратуры юридического факультета Самарского государственного исследовательского института им. Ак. С.П. Королева, г. Самара). Вторая поправка к Конституции (ША: проблема доктринального толкования.//[Электронный pecypc]: URL: «StudNet» (научно-образовательный журнал для студентов и преподавателей), № 11, 2020 г. (Дата обращения: 18.08.2021 г.);

16. Бойся безоружных. В странах, где много оружия, люди реже убивают друг друга.//[Электронный ресурс]: URL: lenta.ru (В. Гринкевич) (Дата обращения: 18.08 .2021 г.);

17. Оксамытный В.В. Многоаспектность источников современной правовой системы Израиля.//[Электронный ресурс]: URL: cyberleninka.ru (Дата обращения: 23.08.2021 г.).

(c) Цветикова Татьяна Викторовна ( tatyna.76@inbox.ru).

Журнал «Современная наука: актуальные проблемы теории и практики»

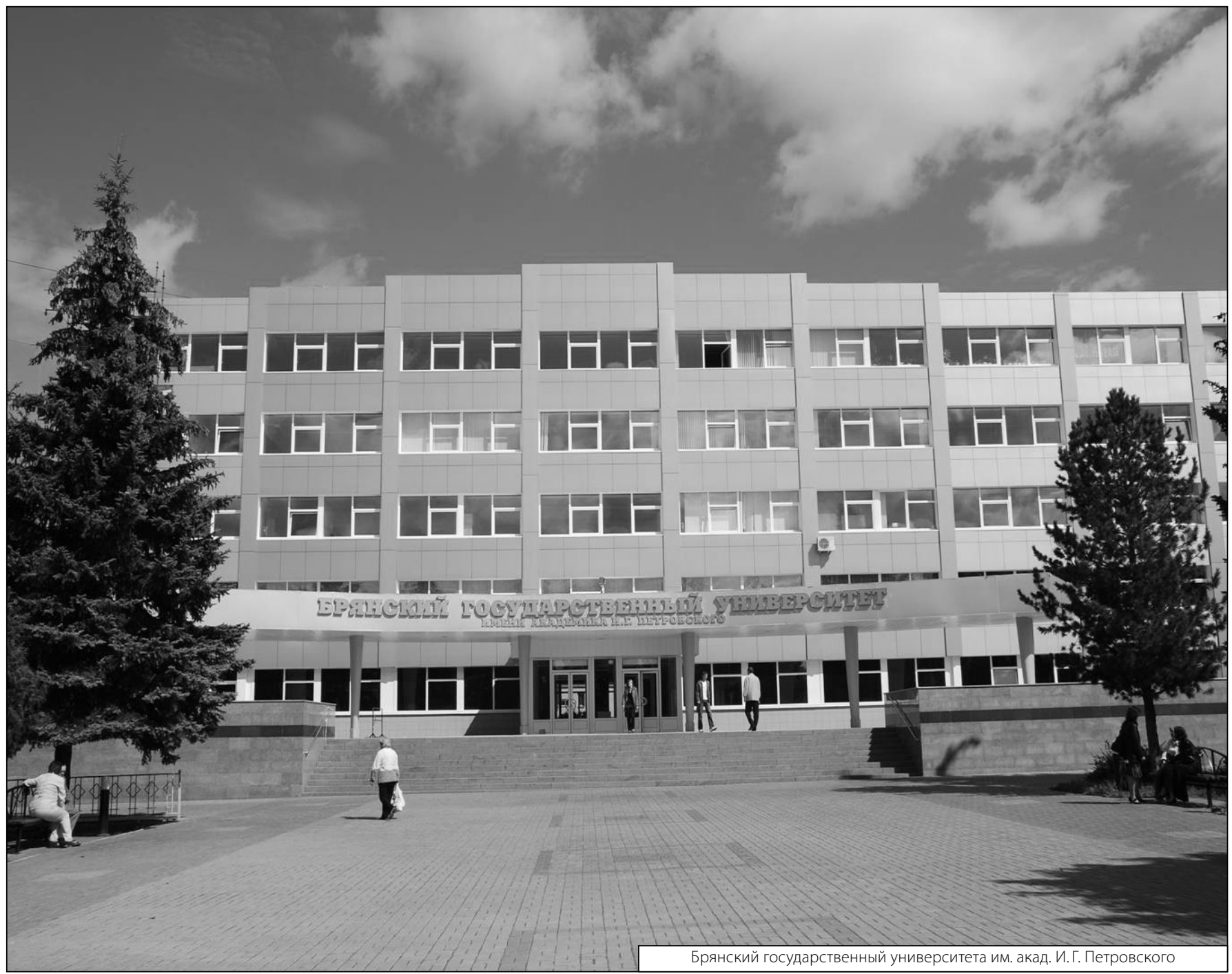

